\title{
Ocorrência de lesões em carcaças de bovinos de corte no Pantanal em função do transporte
}

\author{
Occurrence of carcass bruising of beef cattle in the Pantanal related to time spent transport
}

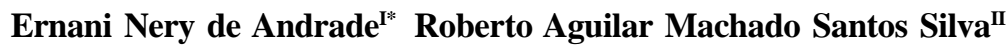 \\ Roberto de Oliveira Roça ${ }^{\text {III }}$ Laura Aparecida Carvalho da Silva ${ }^{\mathrm{I}}$ \\ Heraldo César Gonçalves ${ }^{\mathrm{IV}}$ Rafael Silvio Bonilha Pinheiro ${ }^{\mathrm{I}}$
}

\section{RESUMO}

\begin{abstract}
O trabalho teve como objetivo avaliar a influência do transporte na ocorrência de lesões, em carcaças de bovinos abatidos no Pantanal Sul Matogrossense, por meio da quantificação do número e do tamanho das lesões, assim como a localização da freqüência de ocorrência das lesões nos principais cortes comerciais padronizados para o mercado interno. Do total de 121 carcaças avaliadas, foi observado que 102 (84,3\%) tiveram uma ou mais lesões, totalizando 270 lesões que resultaram na remoção de $56,1 \mathrm{~kg}$ de carne, com média geral de $0,5 \mathrm{~kg}$ por animal ou $0,6 \mathrm{~kg}$ por animal, considerando-se apenas os animais que tiveram lesões. A freqüência de lesões em carcaças de bovinos evidenciou diferença significativa de acordo com as condições de transporte. As maiores proporções de lesões foram encontradas em animais submetidos ao transporte rodoviário por mais de uma hora e distâncias maiores que $70 \mathrm{~km}$, sendo grande parte em estradas não-pavimentadas. Conclui-se que os animais submetidos à série sucessiva de manejo e transportados em estradas não-pavimentadas por longas distâncias apresentaram maior proporção de lesões, sendo que os animais provenientes do lote VI apresentaram maior número de lesões.
\end{abstract}

Palavras-chave: abate de bovinos, caminhão, cortes comerciais, incidência de contusão.

\section{ABSTRACT}

This study aimed to assess the influence of transpor on the occurrence of carcass bruising of cattle slaughtered in the Pantanal, by quantifying the number and size of bruises, locating the frequency of occurrence of bruises in the main commercial cuts standardized for interne market. From a total of 121 carcasses assessed, 102 (84.3\%) had one or more bruises, totaling 270 bruises, which resulted in the removal of $56.1 \mathrm{~kg}$ meat. The frequency of carcass bruises of cattle showed significant difference, according to the conditions of transport. The highest proportions of bruises found in animals submitted to road transport for more than one hour in distances longer than $70 \mathrm{~km}$, a great part of which on dirty toads. The conclusion is that the animals submitted to the successive series of handling and transported on dirty roads for long distances caused the highest proportion of bruises, whereas the animals submitted to lot IV presented the highest number of bruises.

Key words: beef cattle slaughtering, truck, commercial cuts, bruising incidence.

\section{INTRODUÇÃO}

O Pantanal é uma planície estacionalmente inundável, com aproximadamente $139.558 \mathrm{~km}^{2}$ (SILVA et al., 1995), situando-se mais ou menos entre os paralelos de $16^{\circ}$ e $21^{\circ} \mathrm{S}$ e os meridianos de $55^{\circ} \mathrm{W}$. Ele está situado nos Estados de Mato Grosso (sudeste) e Mato Grosso do Sul (noroeste), adentrando pequenas partes na Bolívia e vinculando-se com o Chaco, em prolongamento natural.

O bovino pantaneiro foi a base da economia da região por cerca de três séculos, porém, nas primeiras décadas do século passado, esse tipo local foi substituído gradativamente por raças zebuínas, sendo que nos dias de hoje predomina o gado Nelore.

IPrograma de Pós-graduação em Zootecnia, Faculdade de Medicina Veterinária (FMVZ), Universidade Estadual Paulista

(UNESP). Rua Dr. José Barbosa de Barros, 835, Jardim Paraíso, 18609-085, Botucatu, SP, Brasil. E-mail: ernani@fmvz.unesp.br.

*Autor para correspondência.

"EMBRAPA Pantanal (CPAP), Corumbá, MS, Brasil.

IIIDepartamento de Gestão e Tecnologia Agroindustrial (DGTA), FCAV, UNESP, Botucatu, SP, Brasil.

${ }^{\text {IV }}$ Departamento de Produção e Exploração Animal (DPEA), FMVZ, UNESP, Botucatu, SP, Brasil. 
O sistema de transporte de bovinos no Pantanal é precário e os problemas são agravados pelas inundações e pela falta de estradas. Segundo ROÇA (2001), o transporte de animais para o estabelecimento de abate constitui-se na primeira etapa do abate humanitário, com efeitos significativos na qualidade da carne. Em condições desfavoráveis o sistema de transporte pode levar à morte e ser responsável pelas principais contusões observadas na inspeção postmortem. Ele está relacionado com o estresse dos animais e conseqüentemente com a queda do $\mathrm{pH}$ post-mortem.

Nos últimos anos, o transporte rodoviário prosperou relativamente no Pantanal, basicamente devido ao surgimento de algumas estradas pavimentadas ou outras estradas novas nãopavimentadas.

Este trabalho foi realizado com o objetivo de avaliar a influência do transporte rodoviário na ocorrência de lesões em carcaças de bovinos abatidos no Pantanal Sul Matogrossense, por meio da quantificação do número e do tamanho das lesões e a localização da freqüência de ocorrência das lesões nos principais cortes comerciais brasileiros.

\section{MATERIAL E MÉTODOS}

Local - O estudo foi conduzido no município de Corumbá, região Noroeste do Estado de Mato Grosso do Sul, em dois frigoríficos, um com inspeção estadual e outro com inspeção federal, localizados nos municípios de Ladário e Corumbá, respectivamente.

Origem dos animais - Foram avaliados 121 e um bovinos sãos, da raça Nelore, oriundos de seis propriedades, situadas em três sub-regiões do Pantanal, sendo 34 fêmeas adultas com idade média de 6,5 anos, 26 machos castrados com idade média de 6,5 anos, 61 novilhas com idade média de 2,5 anos. Todos os bovinos foram produzidos sob o sistema extensivo.

Os animais foram divididos em seis lotes, de acordo com a distância da fazenda de origem, as características dos animais e as condições de transporte, contendo 10 a 50 animais cada. Condição I: 11 novilhas com idade média de 2,5 anos, provenientes da região do assentamento rural Taquaral, situado na sub-região do Paraguai, submetidas ao transporte rodoviário em estrada não-pavimentada $(15 \mathrm{~km})$ e em estrada pavimentada (5km), totalizando $20 \mathrm{~km}$. Condição II: 50 novilhas com idade média de 2,5 anos, provenientes da região de Albuquerque, situada na sub-região do Paraguai, submetidas ao transporte rodoviário em estrada não-pavimentada $(5 \mathrm{~km})$ e em estrada pavimentada $(45 \mathrm{~km})$, totalizando $50 \mathrm{~km}$. Condição III: 11 vacas com idade aproximada (baseada na informação do criador) de 8 a 10 anos, provenientes da região de Albuquerque, situada na sub-região do Paraguai, submetidas ao transporte rodoviário em estrada não-pavimentada $(19 \mathrm{~km})$ e em estrada pavimentada $(31 \mathrm{~km})$, totalizando $50 \mathrm{~km}$. Condição IV: 19 animais (uma vaca com idade aproximada de quatro anos, com base na informação do criador, e 18 machos castrados de 3,5 a quatro anos), provenientes da região de Maria Coelho, situada na sub-região do Paraguai, submetidos ao transporte rodoviário em estrada nãopavimentada (52km) e em estrada pavimentada $(18 \mathrm{~km})$, totalizando $70 \mathrm{~km}$. Condição V: 10 animais (duas vacas com idade aproximada de seis a oito anos, com base na informação do criador e 8 machos castrado de oito a 10 anos), provenientes da sub-região do Nabileque, submetidos ao transporte rodoviário em estrada nãopavimentada (68km) e em estrada pavimentada (120km), totalizando $188 \mathrm{~km}$. Condição VI: 20 vacas com idade aproximada, a partir da informação do criador, de seis a sete anos, provenientes da sub-região do Paiaguás, submetidas aos transportes por comitiva $(351 \mathrm{~km})$ e rodoviário em estrada não-pavimentada $(74 \mathrm{~km})$ e em estrada pavimentada $(46 \mathrm{~km})$, totalizando $471 \mathrm{~km}$.

Transporte - Os bovinos oriundos da condição I foram submetidos ao transporte rodoviário no período das 15 h às 15 h50min do dia 15/07/2003. A distância percorrida foi de $20 \mathrm{~km}$, desde a propriedade de origem, situada na região oeste da sub-região do Paraguai, até o frigorífico, que encontra-se situado na região Centro-Oeste da sub-região da Paraguai. O tempo decorrido desde a saída dos animais da propriedade de origem até o ato de insensibilização no frigorífico foi de 17 horas. Durante o período de transporte e permanência no frigorífico, os animais permaneceram em jejum. O abate realizou-se no dia 16/ 07/2003 às 8h.

Os bovinos procedentes da condição II foram submetidos ao transporte rodoviário no período das 16 h às 16 h40min do dia 17/07/2003. A distância percorrida foi de $50 \mathrm{~km}$, desde a propriedade de origem situada na região sul da sub-região do Paraguai até o frigorífico. O tempo gasto desde a saída dos animais da propriedade de origem até o ato de insensibilização no frigorífico foi de $22 \mathrm{~h}$. Durante o período de transporte e permanência no frigorífico, os animais permaneceram em jejum. $\mathrm{O}$ abate foi realizado no dia 18/07/2003 às $14 \mathrm{~h}$.

Os bovinos pertencentes à condição III foram submetidos ao transporte rodoviário no período das 15 h às $16 \mathrm{~h} 10 \mathrm{~min}$ do dia 17/07/2003. A distância percorrida foi de $50 \mathrm{~km}$, desde a propriedade de origem situada na região sul da sub-região do Paraguai até o frigorífico. O tempo gasto desde a saída dos animais 
da propriedade de origem até o ato de insensibilização no frigorífico foi de 22horas e 10 minutos. Durante o período de transporte e permanência no frigorífico, os animais permaneceram em jejum. $\mathrm{O}$ abate foi realizado no dia 18/07/2003 às 13h10min.

Os bovinos oriundos da condição IV foram submetidos ao transporte rodoviário no período das 10h30min às 11h35min do dia 17/07/2003. A distância percorrida foi de $70 \mathrm{~km}$, desde a propriedade de origem situada na região sudeste da sub-região do Paraguai até o frigorífico. O tempo gasto desde a saída dos animais da propriedade de origem até o ato de insensibilização no frigorífico foi de 20 horas e 30 minutos. Durante o período de transporte e permanência no frigorífico, os animais permaneceram em jejum. $O$ abate foi realizado no dia 18/07/03 às 7 h.

Os bovinos procedentes da condição $\mathrm{V}$ foram submetidos ao transporte rodoviário no período das 8h30min às 11h10min do dia 28/07/2003. A distância percorrida foi de $188 \mathrm{~km}$, desde a propriedade de origem situada na região centro-oeste da sub-região do Nabileque até o frigorífico. O tempo gasto desde a saída dos animais da propriedade de origem até o ato de insensibilização no frigorífico foi de 22 horas 30 minutos. Durante o período de transporte e permanência no frigorífico, os animais permaneceram em jejum. O abate foi realizado no dia 29/07/2003 às 7 h.

Os bovinos pertencentes à condição VI foram transportados em comitiva do dia 18/07/2003 ao dia 27/07/2003, percorrendo uma distância de $200 \mathrm{~km}$, deste a propriedade de origem situada na sub-região do Paiaguás até o leilão, situado na sub-região da Nhecolândia, totalizando 10 dias de transporte em comitiva, com uma média de 10 horas de transporte/ dia. O embarque no caminhão ocorreu no dia 28/07/ 2003 no período da manhã, quando foram submetidos ao transporte rodoviário por aproximadamente quatro horas, percorrendo uma distância de $120 \mathrm{~km}$, desde o leilão até o desembarque no frigorífico. O tempo gasto desde a saída dos animais da propriedade de origem até $o$ ato de insensibilização no frigorífico foi de 268 horas e 30 minutos e/ou aproximadamente 104 horas, considerando-se apenas os períodos de transporte. Durante o transporte por comitiva, os animais pastejavam e bebiam água e durante o transporte rodoviário e a permanência no frigorífico os animais permaneceram em jejum. $\mathrm{O}$ abate foi realizado no dia 29/07/2003 às 10h30min.

$\mathrm{O}$ transporte rodoviário referente às condições I, II, III, IV, V e VI foi realizado por diferentes motoristas, utilizando veículo com capacidade para 18 cabeças de gado. A comitiva responsável pelo transporte relativo à condição VI era composta por sete peões boiadeiros, especializados nesse tipo de atividade, e um cozinheiro, que utilizaram em torno de 20 eqüinos e/ou mulas e burros.

Frigorífico - No frigorífico, os bovinos foram submetidos à inspeção ante mortem e a idênticos manejos pré-abate: jejum e dieta hídrica de 12 horas. $\mathrm{O}$ banho de aspersão dos animais foi realizado com água clorada, à temperatura ambiente, durante seis a 10 minutos. Os animais foram abatidos, suspensos por meio de guincho elétrico e processados com o auxílio de transportador aéreo automático.

Sistema de classificação de lesões - Durante o abate, cada carcaça foi avaliada e numerada em ficha individual, onde registrava-se o número e o tamanho das lesões, conforme formulário próprio. Cada carcaça foi numerada obedecendo à seqüência e velocidade normal de abate do estabelecimento.

As lesões de carcaça foram visualmente identificadas e classificadas. As classificações das lesões foram realizadas durante as avaliações das carcaças.

Foi adotado um sistema próprio de classificação. As lesões foram classificadas em cinco categorias básicas, de acordo com o tamanho da área de superfície da lesão, como segue: "tamanho 1" - de 1 a 5cm em diâmetro, "tamanho 2" - de 6 a $10 \mathrm{~cm}$ em diâmetro, "tamanho 3" de 11 a $15 \mathrm{~cm}$ em diâmetro, "tamanho 4" de 16 a 20cm em diâmetro e "tamanho 5" de um diâmetro maior que $21 \mathrm{~cm}$. Lesão abaixo de $1 \mathrm{~cm}$ de diâmetro não foi registrada.

Quantificação das lesões por cortes comerciais - A ocorrência e a localização das lesões nos cortes também foram anotadas nas fichas individuais correspondentes a cada carcaça, conforme um formulário próprio.

Foram avaliadas as presenças de lesões nos cortes comerciais padronizados para o mercado interno pela Portaria SIPA nº 5, de 8/11/1988 (BRASIL, 1988). Os seguintes cortes comerciais do quarto dianteiro foram avaliados: paleta, músculo, cupim, acém, pescoço, peito e costela do dianteiro. Foram também avaliados os seguintes cortes comerciais do quarto traseiro: costela do traseiro e vazio (fraldinha), da ponta de agulha e contrafilé, capa de filé, filé-mignon, abade-filé, picanha, alcatra, maminha-da-alcatra, coxão de dentro (chã-de-dentro), lagarto, coxão de fora (chã-defora), patinho e músculo traseiro, do traseiro-serrote.

As carcaças que apresentaram lesões foram submetidas à remoção dos tecidos afetados na operação de toalete, conforme procedimento próprio de cada frigorífico.

As lesões removidas foram coletadas e separadas em sacos plásticos individualmente, de 
acordo com o número da carcaça com lesão e o peso total foi anotado segundo o lote de origem. Todas as lesões foram pesadas e medidas no laboratório da Empresa Brasileira de Pesquisa Agropecuária - Embrapa Pantanal.

Avaliação estatística - A freqüência de lesões em carcaças de bovinos entre os lotes foi comparada pelo Teste do Qui-quadrado (X2), em nível de significância (NS) de 1\%. O teste não paramétrico de Kruskal-Wallis foi utilizado para comparações múltiplas entre médias da condição para as características: tamanho das lesões, idade das lesões em função da sua coloração e a incidência de lesões nos cortes comerciais. Consideraram-se significativas as diferenças com $\mathrm{P}<0,01$. O Sistema de Análises Estatísticas e Genéticas - SAEG 9.0 (UFU, 1997) foi utilizado para análise dos dados.

\section{RESULTADOS E DISCUSSÃO}

Os resultados da influência do transporte rodoviário na incidência de lesões e no peso dos tecidos lesionados retirados de carcaças de bovinos ao abate em função dos lotes são apresentados na tabela 1. Do total de 121 carcaças avaliadas, foi constatado que 102 $(84,3 \%)$ tiveram uma ou mais lesões, totalizando 270 lesões que resultaram na remoção de $56,1 \mathrm{~kg}$ de carne, com média geral de $0,5 \mathrm{~kg}$ por animal ou $0,6 \mathrm{~kg}$ por animal, considerando-se apenas os animais que tiveram lesões (Tabela 1). TARRANT \& GRANDIN (2000) asseguram que as principais perdas durante o transporte rodoviário dos bovinos estão relacionadas fundamentalmente às contusões e ao estresse. KNOWLES (1999) afirma que o transporte rodoviário, em condições desfavoráveis, pode conduzir a contusões ou provocar morte ou perdas de peso e estresse dos animais. A mortalidade de bovinos durante o transporte é extremamente baixa (KNOWLES, 1995). BRAGGION \& SILVA(2004), em estudo na mesma região, demonstraram que $100 \%$ dos bovinos abatidos em frigorífico localizado no Pantanal Sul Mato-grossense apresentavam lesões, sendo que 33,08\% foram devidas ao transporte inadequado.

Foi observada diferença nas proporções de carcaças com lesões entre os lotes (Tabela 1). A maior proporção de lesão foi encontrada em animais oriundos dos lotes IV e VI, submetidos ao transporte rodoviário por mais de uma hora e distâncias superiores a 70km, sendo grande parte em estradas não-pavimentadas. A menor proporção de lesões foi encontrata em animais pertencentes o lote III, correspondente ao transporte em estradas pavimentadas. Esse resultado não teve relação com o espaço ocupado por animal, ou seja, a densidade de carga durante o transporte de caminhão sob o qual os animais foram submetidos, levando em conta que a menor proporção de lesões foram encontradas em animais pertencentes o lote III, com 11 bovinos. Os resultados obtidos demonstraram que a utilização de estradas não-pavimentadas e longas distâncias interferem na proporção de lesões. Esses resultados estão em concordância com os encontrados por JOAQUIM (2002), que observou que as condições da estrada são fatores importantes, sob o aspecto de bem-estar animal, sendo que animais que são transportados por longas distâncias em estradas nãopavimentadas apresentam, na prática, alta incidência de contusões, como resultado dos solavancos, freadas e desvios bruscos a que estão sujeitos os caminhões boiadeiros.

Os animais provenientes do lote VI foram transportados em comitiva por 10 dias, numa distância de $200 \mathrm{~km}$ desde a propriedade de origem até a fazenda realizadora de leilão, onde foram submetidos a inúmeros

Tabela 1 - Incidência de lesões e peso dos tecidos retirados de carcaças nas diferentes condições de transporte

\begin{tabular}{|c|c|c|c|c|c|c|c|c|}
\hline \multirow{2}{*}{ Grupo } & \multirow{2}{*}{$\mathrm{N}^{\mathrm{o}}$} & \multicolumn{2}{|c|}{------Carcaças------- } & \multirow{2}{*}{ Total de lesões } & \multirow{2}{*}{$\begin{array}{l}\text { \% de carcaças } \\
\text { com lesões** }\end{array}$} & \multicolumn{3}{|c|}{---Peso dos tecidos removidos (kg)--- } \\
\hline & & Sem lesão & Com lesão & & & Total & Peso/lesão & Peso/animal \\
\hline Condição I* & 11 & 2 & 9 & 21 & 81,81 a b & 1,9 & 0,1 & 0,2 \\
\hline Condição II* & 50 & 9 & 41 & 80 & $82,00 \mathrm{a} b$ & 17,3 & 0,2 & 0,4 \\
\hline Condição III* & 11 & 6 & 5 & 15 & 45,45 a & 0,6 & 0,0 & 0,1 \\
\hline Condição IV* & 19 & 1 & 18 & 33 & $94,73 \quad b$ & 12,9 & 0,4 & 0,8 \\
\hline Condição V* & 10 & 1 & 9 & 28 & $90,00 \mathrm{a} b$ & 3,2 & 0,1 & 0,3 \\
\hline Condição VI* & 20 & 0 & 20 & 93 & 100 & 20,2 & 0,3 & 1,0 \\
\hline Total & 121 & 19 & 102 & 270 & & 56,1 & 0,3 & 0,6 \\
\hline
\end{tabular}

**Médias na mesma coluna seguidas de diferentes letras diferem significativamente $(\mathrm{P}<0,01)$ pelo teste qui-quadrado.

*Condição I - transporte rodoviário (20 quilômetros). Condição II - transporte rodoviário (50 quilômetros). Condição III - transporte rodoviário (50 quilômetros). Condição IV- transporte rodoviário (70 quilômetros). Condição V - transporte rodoviário (188 quilômetros). Condição VI - transporte por comitiva (351 quilômetros) e rodoviário (120 quilômetros) totalizando $471 \mathrm{~km}$.

Ciência Rural, v.38, n.7, out, 2008. 
manejos até serem leiloados e transportados por aproximadamente quatro horas, numa distância de $120 \mathrm{~km}$, desde o leilão até o frigorífico. Estes animais apresentaram $100 \%$ de freqüência de lesões em carcaças. Esse achado provavelmente está relacionado à série sucessiva de procedimentos de manejo a qual os animais foram submetidos, ficando desta maneira expostos a sofrerem lesões. ELDRIDGE et al. (1984) concluíram que bovinos comercializados em leilões apresentaram maior quantidade de lesões e mais severas que aqueles enviados diretamente para o matadouro. Tais relatos reforçam os resultados apresentados na tabela 1. Para McNALLY \& WARRISS (1996), a presença de contusões mostra uma associação significativa com a distância de transporte. No entanto, RAMSAY et al. (1976) afirmaram que, além da distância de transporte, também é importante considerar o movimento dos bovinos dentro do caminhão ou outro meio de condução durante a aceleração e a desaceleração e que este fator pode ser mais crítico na incidência de lesões maiores.

Na tabela 2 são apresentadas as médias dos tamanhos das lesões em função das condições de transporte, sendo a maior média encontrada em animais pertencentes o lote VI. Esse achado provavelmente está relacionado à série sucessiva de manejo a qual os animais foram submetidos no transporte e durante a triagem dos animais para o leilão. Como conseqüência, essas carcaças apresentaram $100 \%$ de freqüência de lesões. A média de animais leiloados a cada leilão é de 2.500 animais. Com isso, antes de serem leiloados, os animais são expostos a uma série de manejo no curral, brete, tronco de contenção, entre outros. Os bovinos são vacinados, separados por categoria, em seguida por lote e por último por proprietários. Vale ressaltar que, do total de 20 carcaças avaliadas pertencentes o lote IV, $100 \%$ tiveram uma ou mais lesões, totalizando 93 lesões que resultaram na remoção de 20,3kg de carne, com média por animal de 1,0kg.

$\mathrm{Na}$ tabela 3 estão apresentadas as percentagens de lesões nos cortes comerciais de

Tabela 2 - Médias dos tamanhos de lesões em função das condições de transporte

\begin{tabular}{lcc}
\hline Origem & Médias dos dados & Total de lesões \\
\hline Condição I & 1,38 a & 21 \\
Condição II & $1,76 \mathrm{a}$ & 80 \\
Condição III & $1,33 \mathrm{a}$ & 15 \\
Condição V & $1,36 \mathrm{a}$ & 33 \\
Condição V & $1.57 \mathrm{a}$ & 28 \\
Condição VI & $3,00 \mathrm{~b}$ & 93 \\
\hline
\end{tabular}

Médias com letras distintas na mesma coluna diferem entre si (P $<0,01)$.
Tabela 3 - Distribuição e freqüência das lesões pelos diferentes cortes comerciais.

\begin{tabular}{lc} 
Cortes comerciais & $\begin{array}{c}\text { Percentual de lesões nos cortes } \\
\text { comerciais }\end{array}$ \\
\hline Lagarto & 28,1 \\
Alcatra & 15,9 \\
Coxão duro & 14,8 \\
Costela & 12,2 \\
Paleta & 11,5 \\
Contrafilé & 3,7 \\
Fraldinha & 3,1 \\
Peito & 2,6 \\
Cupim & 1,5 \\
Patinho & 1,4 \\
Pescoço & 1,1 \\
Coxão mole & 1,1 \\
Maminha & 1,1 \\
Músculo & 0,7 \\
Picanha & 0,4 \\
Filé-mignon & 0,4 \\
Pata dianteira & 0,4 \\
Total & 100 \\
\hline
\end{tabular}

carcaças de animais transportados por vias rodoviárias. Os seguintes cortes comerciais apresentaram a maior freqüência de lesões lagarto (28,1\%), alcatra $(15,9 \%)$, coxão duro (14,8\%), costela (12,2\%), paleta $(11,5 \%)$ e contrafilé (3,7\%) (Tabela 3).

\section{CONCLUSÕES}

A série sucessiva de manejo e o transporte em estradas não-pavimentadas por longas distâncias causou maior proporção de lesões em carcaça. O maior número de lesões em carcaças foi registrado nos animais provenientes da condição de acompanhamento VI, na qual foram comercializados em leilão e submetidos aos transportes em comitiva e rodoviário. Novos estudos devem ser implementados para reduzir os problemas do manejo pré-abate.

\section{COMITÊ DE ÉTICA E BIOSSEGURANÇA}

O trabalho foi conduzido sob as condições normais e oficiais de acordo com a legislação do Serviço de Inspeção Federal. Não houve nenhuma modificação do manejo ou tecnologia de abate. Aprovado pela Câmara de Ética em Experimentação Animal (CEEA), protocolo nº 159/2003 CEEA.

\section{REFERÊNCIAS}

BRAGGION, M.; SILVA, R.A.M.S. Quantificação de lesões em carcaças de bovinos abatidos em frigoríficos no 
Pantanal Sul-Mato-Grossense. Corumbá: Embrapa - CPAP, 2004. p.1-4, (Comunicado Técnico n.45)

BRASIL. Secretaria de Inspeção de Produto Animal (SIPA), Ministério da Agricultura. Portaria n.5 de 08 de novembro de 1988. Padronização dos cortes de carne bovina. Brasília, 1988.

ELDRIDGE. G.A. et al. Bruising and method of marketing cattle. Production Australian Society Animal Production, v.15, p.675, 1984.

JOAQUIM, C.F. Efeitos da distância de transporte em parâmetros post-mortem de carcaças bovinas. 2002. 69f. Dissertação (Mestrado em Medicina Veterinária) - Faculdade de Medicina Veterinária e Zootecnia, Universidade Estadual Paulista, Botucatu.

KNOWLES, T.G. A review of post transport mortality among yourge calves. Veterinary Record, v.137, p.406-407, 1995.

KNOWLES, T.G. A review of the road transport of cattle. Veterinary Record, v.144, n.8, p.197-201, 1999.
McNALLY, P.W.; WARRISS, P.D. Recent bruising in cattle at abattoirs. Veterinary Record, v.138, p.126-128, 1996.

RAMSAY, W.R. et al. The effect of tipping of horns and interruption of journey on bruising in cattle. Australian Veterinary Journal, v.52, p.285-286, 1976.

ROÇA, R.O. Abate humanitário de bovinos. Revista de Educação Continuada do CRMV-SP, v.4, n.2, p.73-85, 2001.

SAEG - Sistema de análise estatística e genéticas. (Versão 7.0). Viçosa, MG: UFV, 1997. 54p. (Manual do usuário).

SILVA, J.S.V. et al. Delimitação do Pantanal brasileiro e suas sub-regiões. In: ENCONTRO SOBRE SENSORIAMENTO REMOTO APLICADO A ESTUDOS NO PANTANAL, 1995, São José dos Campos, SP. Anais... São José dos Campos: INEP, 1995. p.9-10.

TARRANT, P.V.; GRANDIN, T. Cattle transport. In: GRANDIN, T. Livestock handling and transport. 2.ed. Oxon: Cabi, 2000. p.151-173. 